\title{
Peringatan Dini Tanah Longsor Berdasarkan Kelembaban Tanah Secara Jarak Jauh Menggunakan Sensor FC-28 dan Node MCU
}

\author{
Agus Setyawan, Jatmiko Endro Suseno, Ratna Dewi Winesthi dan Sela Ade Otaviana
}

Departemen Fisika, Fakultas Sains dan Matematika, Universitas Diponegoro, Jl. Prof. Sudharto Tembalang, Semarang, Indonesia; e-mail: agussetyawan@fisika.fsm.undip.ac.id

\begin{abstract}
ABSTRAK
Tanah longsor merupakan salah satu bencana yang sering terjadi di Indonesia, terutama di daerah pegunungan, lembah dan perbukitan dengan kondisi lereng yang tidak stabil. Saat musim hujan tiba maka kadar air yang berlebihan mengakibatkan tanah longsor. Bencana tanah longsor dapat menyebabkan banyak kerugian antara lain: kematian, gangguan infrastruktur jalan dan rusaknya lahan pertanian. Hal tersebut dipengaruhi oleh 2 faktor utama yaitu kemiringan lereng dan kelembaban. Penelitian ini bertujuan untuk meminimalkan korban jiwa dengan merancang alat pendeteksi peringatan dini bencana tanah longsor menggunakan sensor Soil Moisture FC-28 dan NodeMcu longsor yang terhubung ke android melalui telegram, sms dan buzzer. Sensor soil moisture FC-28 dipakai untuk mendeteksi parameter kelembaban tanah. Pengujian potensi terjadinya tanah longsor didesain dalam 5 variasi kemiringan untuk mendapatkan nilai kembebaban yang bervariasi. Alat dirancang dengan 2 kondisi yaitu status siaga dan bahaya. Hasil pengujian menunjukkan bahwa kondisi siaga terjadi pada kelembaban antara 27\% - 54\% dengan kemiringan lereng antara 25o -35o dan kondisi bahaya terjadi saat kelembaban lebih dari 54\%. Peringatan dini akan terkirim melalui pesan singkat ada aplikasi telegram messenger saat kondisi status siaga, sedangkan alarm akan berbunyi pada saat status bahaya. Alat ini akan sangat bermanfaat bagi warga yang tinggal didaerah rawan bencana longsor, karena dengan adanya tanda peringatan dini warga diharapkan masih mempunyai waktu untuk menyelamatkan diri sehingga korban jiwa dapat diminimalkan.
\end{abstract}

Kata kunci: Tanah Longsor, Kemiringan lereng, kelembaban tanah, Soil Moisture FC-28, NodeMCU, Telegram Messenger

\begin{abstract}
Landslide is one of the most frequent disasters in Indonesia, especially in hilly areas, valleys and volcanoes. Geographical conditions which are generally mountainous areas and have slopes make the soil unstable. Landslide occurs in the rainy season, when the water content is excessive. Landslide disaster caused many losses, such as: death of people, disruption of infrastructure and damage agricultural. There are two main factors influences in lanslides: slope and humidity. The aims of study is to minimize fatalities by designing a landslide early warning detector using the Soil Moisture FC-28 sensor and the NodeMcu landslide connected to Android via telegram, SMS and buzzer. Soil Moisture Fc-28 Sensor were used to detected the humidity of soil. Testing potential landslide ware designed in five slope to purpose the varying humidity causes. The equipment design in two conditions; alert and danger. The results show that the alert condition occurs when the humidity between $27 \%-54 \%$ with a slope $25^{\circ}-35^{\circ}$ respectively, moreover the danger conditions occurs when the humidity more than $54 \%$. Early warning system will be sent via short message using messenger telegram when the status is alert, while the alarm will ringging when the status is danger. The tool is very useful for people surronding area, with an existence of early warning system in disaster area, they still have time to evacuate and the casualties can be minimized.
\end{abstract}

Keywords: Landslide, Slope, Humidity, Soil Moisture FC-28, NodeMCU, Telegram Messenger

Citation: Setyawan, A., Suseno, JE., Winesthi RD., dan Otaviana, SA. (2020). Peringatan Dini Tanah Longsor Berdasarkan Kelembaban Tanah Secara Jarak Jauh Menggunakan Sensor FC-28 dan Node MCU. 18(2), 242-246, doi:10.14710/jil.18.2.242-246

\section{Latar Belakang}

Tanah longsor adalah perpindahan massa batuan, regolit dan tanah dari tempat yang tinggi ke tempat yang rendah karena pengaruh gaya gravitasi (Hary, 2006). Pada prinsipnya tanah longsor terjadi bila gaya pendorong pada lereng lebih besar dari pada gaya penahan. Gaya penahan pada umunya dipengaruhi oleh kekuatan batuan dan kepadatan tanah. Gaya pendorong dipengaruhi oleh besarnya sudut lereng, beban serta berat jenis batuan (Nandi,
2007), lebih jauh Tejo dkk (2016) menjelaskan bahwa factor utama terjadinya longsor adalah kemiringan lereng dan curah hujan. Lereng dikatakan curam apabila sudut kemiringan lerengnya sebesar $30^{\circ}$

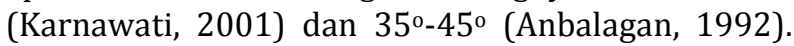
Curah hujan yang tinggi dan berlangsung lama sangat berperan dalam memicu terjadinya gerakan tanah (longsor). Air hujan yang meresap ke dalam lereng dapat meningkatkan kejenuhan tanah pada lereng, yang berakibat merenggangkan ikatan partikel tanah 
dan akhirnya massa tanah terangkut oleh aliran air dalam lereng (Silvianingsih dkk 2015; Fina dkk. 2015). Peningkatan kadar air menyebabkan penurunan nilai sifat mekanik (kohesi dan sudut geser dalam) yang berdampak terhadap penurunan kestabilan lereng (Gati dan Caroline, 2018).

Risiko jatuhnya korban jiwa yang lebih besar dapat dihindari melalui upaya mitigasi dengan memanfaatkan kemajuan teknologi. Adanya alat yang mampu mengukur parameter utama tanah longsor dapat dijadikan sebagai mitigasi dini karena sebelum terjadi bencana tanah longsor terdapat perubahan besaran fisis tanah yang dinyatakan oleh parameter (Paimin dkk 2009; Mudhrikah, 2015; Lutfiyana dkk 2017). Maka pengukuran parameter relatif akurat dalam menentukan potensi kelongsoran suatu wilayah sangat diperlukan. Terkait hal tersebut, perlu mengembangkan alat mitigasi dini bencana tanah longsor dengan membuat rancang bangun alat pendeteksi tanah longsor menggunakan sensor fc-28 dan node mcu Berbasis Wifi, telegram, sms dan buzzer yang diharapkan mampu mengurangi dampak korban jiwa. Beberapa penelitian tentang pembuatan alat pendeteksi dini tanah longsor yang sudah dilakukan antara lain: Purwarupa sistem pendeteksi tanah longsor menggunakan ultrasonik dan infrared dengan notifikasi sms (Widhiantoro, 2017). Rancang bangun sistem peringatan dini tanah longsor berbasis mikrokontroler atmega328 menggunakan metode penginderaan berat (Mardhatillah dan Wildian, 2017). Perancangan Deteksi Longsor Di Bukit Watu Buceng Dusun Ketos Desa Wonodadi Kulonsari (Ridho'I dkk, 2015). Meskipun sudah ada beberapa penelitian terkait detektor tanah longsor, tapi belum ada yang memfokuskan pada tingkat kelembaban tanah maka pada tulisan ini fokus pada sensor kelembaban tanah yang terhubung dengan notifikasi di smartphone melalui aplikasi telegram dan sms yang berisi informasi nilai kelembaban tanah, kemiringan lereng dan status bencananya serta buzzer sebagai notifikasi tambahan. Tujuan dari penelitian ini adalah membuat alat peringatan dini bencana tanah longsor sebagai antisipasi keselamatan warga sekitar sehingga diharapkan mampu mengurangi korban jiwa.

\section{Metode Penelitian}

Uji coba penelitian dilakukan di Laboratorium Elektronika dan Instrumentasi, Departemen Fisika Universitas Diponegoro dengan membuat prototype yang menyerupai lereng dan memvariasi kemiringannya. Penelitian dilakukan dengan membuat sistem rancang bangun untuk mendeteksi dini tanah longsor dengan memberikan peringatan dini tanah longsor berupa notifikasi pada smartphone menggunakan aplikasi telegram. Pada aplikasi telegram terdapat telegram bot dimana telegram bot dapat di koneksikan dengan sebuah sistem yang menggunakan mikrokontroller NodeMCU ESP8266 sebagai pengendali sekaligus sebagai modul wifi sehingga sistem terkoneksi dengan internet. Pada prinsipnya NodeMCU bekerja dengan cara menerima data dari peralatan input berupa sensor kelembaban tanah. Perintah program yang dibaca oleh NodeMCU yaitu pembacaan nilai kelembaban tanah oleh sensor FC-28 kemudian diproses oleh NodeMCU untuk kemudian dikirimkan ke telegram. Apabila pembacaan kelembaban tanah berada pada status bahaya maka NodeMCU secara otomatis menyalakan buzzer (buzzer ON). Secara keseluruhan rangkaian sistem pendeteksi dini tanah longsor dapat dilihat pada gambar 1 . Alat ini menggunakan tegangan $5 \mathrm{~V} \mathrm{DC}$ dimana tegangan diperoleh dari tegangan $220 \mathrm{~V} \mathrm{AC}$ kemudian disearahkan oleh adapter menjadi 5V DC. Sensor kelembaban tanah dan buzzer bekerja mengunakan tegangan 3,3V DC yang disuplai dari pin Vcc NodeMCU.

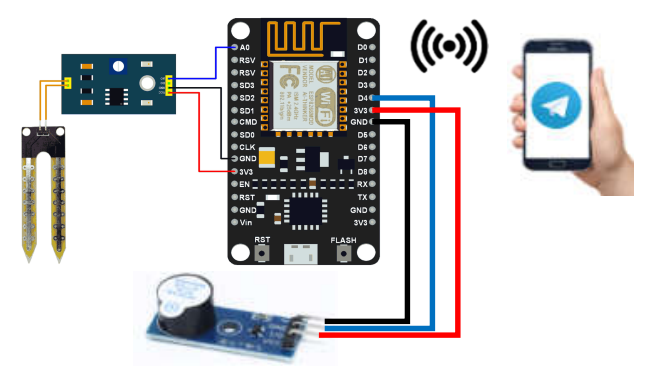

Gambar 1 Rangkaian sistem pendeteksi dini tanah longsor

\section{Pengujian Alat}

Pengujian komponen dilakukan untuk memastikan alat sudah berfungsi dengan baik sesuai sistem yang diinginkan. Pengujian akan dibagi menjadi beberapa bagian, diantaranya karakterisasi sensor kelembaban tanah, kalibrasi sensor kelembaban tanah (Yahwe dkk, 2016), pembuatan telegram bot, pengujian mengirim data ke telegram bot dan pengujian seluruh sistem.

\section{Karakterisasi Sensor Kelembaban Tanah}

Sensor kelembaban tanah FC-28 dikarakterisasi dengan memvariasi ketinggian probe sensor FC-28 yang ditancapkan ke tanah, diperoleh hubungan ketinggian sensor FC-28 yang ditancapkan ke tanah atau air dengan nilai tegangan. Data hasil pengukuran dapat dilihat pada tabel 1.

Tabel 1 Data Hasil pengukuran karakterisasi sensor kelembaban tanah FC-28

\begin{tabular}{|c|c|c|}
\hline \multirow[b]{2}{*}{ Batas probe } & \multicolumn{2}{|c|}{ Tegangan sensor } \\
\hline & $\begin{array}{l}\text { Medium tanah } \\
\text { basah (V) }\end{array}$ & Medium air (V) \\
\hline 1. & 1.94 & 1.7 \\
\hline 2. & 1.28 & 1.55 \\
\hline 3. & 1.15 & 1.30 \\
\hline 4. & 0.97 & 1.15 \\
\hline 5. & 0.88 & 0.95 \\
\hline 6. & 0.79 & 0.82 \\
\hline 7. & 0.68 & 0.67 \\
\hline
\end{tabular}


Dari data tersebut dapat diperoleh hubungan batas probe dengan nilai tegangan adalah semakin dalam probe sensor FC-28 menancap ke tanah maka nilai tegangan semakin menurun, artinya bahwa semakin banyak kontak antara tanah dan air dengan kedua elektrode sensor, maka semakin sensitif sensor tersebut digunakan. Dalam rumus $\mathrm{V}=\mathrm{I} \times \mathrm{R}$, dengan $\mathrm{V}$ adalah tegangan (Volt), I adalah arus (Ampere) dan $\mathrm{R}$ adalah hambatan (ohm); terlihat secara empiris bahwa hambatan berbanding lurus dengan tegangan dimana semakin kecil tegangan maka semakin kecil nilai resistansi. Berdasarkan hasil karakterisasi sensor, maka pengukuran yang paling baik digunakan untuk sensor FC-28 adalah tertancap semuanya ke tanah.

\section{Kalibrasi Sensor Kelembaban Tanah}

Kalibrasi sensor kelembaban tanah dilakukan untuk memastikan sensor kelembaban tanah pada alat ini memiliki hasil nilai sesuai dengan alat standar yang sudah terkalibrasi. Cara kalibrasi yaitu dengan membandingkan hasil kelembaban yang terdeteksi oleh sensor kelembaban tanah dengan soil tester. Tabel 2 menunjukkan hasil kalibrasi sensor kelembaban tanah.

Tabel 2 Kalibrasi Sensor Kelembaban Tanah

\begin{tabular}{ccccc}
\hline No. & $\begin{array}{c}\text { Kelembaban } \\
\text { Sensor (\%) }\end{array}$ & $\begin{array}{c}\text { Kelembaban } \\
\text { Soil Tester }\end{array}$ & $\begin{array}{c}\text { Kelembaban } \\
\text { Soil Tester } \\
\text { (\%) }\end{array}$ & $\begin{array}{c}\text { Error } \\
\text { (\%) }\end{array}$ \\
\hline 1. & 0 & 0 & 0 & 0.00 \\
2. & 14 & 1 & 10 & 40.00 \\
3. & 24 & 2 & 20 & 20.00 \\
4. & 33 & 3 & 30 & 10.00 \\
5. & 41 & 4 & 40 & 2.50 \\
6. & 53 & 5 & 50 & 6.00 \\
7. & 65 & 6 & 60 & 8.33 \\
8. & 76 & 7 & 70 & 8.57 \\
9. & 82 & 8 & 80 & 2.50 \\
10. & 94 & 9 & 90 & 4.44 \\
11. & 100 & 10 & 100 & 0.00 \\
\hline \multicolumn{5}{c}{}
\end{tabular}

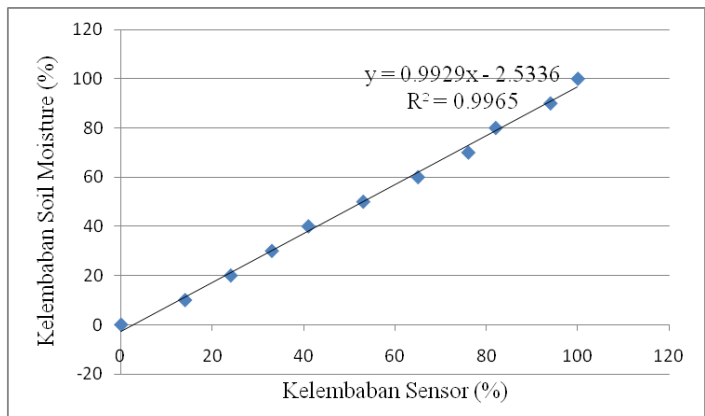

Gambar 2 Grafik regresi linier sensor kelembaban tanah dengan soil tester

Gambar 2 menunjukkan hasil pengujian perbandingan kelembaban yang terdeteksi oleh sensor kelembaban tanah dengan soil tester, diperoleh error rata-rata sebesar 9,30\%. Dengan hasil grafik lineritas $y=0,9929 x-2,5336$ dan nilai $R^{2}$ $=0,9965$. Dari data yang diperoleh pada saat pengujian diketahui bahwa sensor kelembaban tanah memiliki nilai akurasi yang tinggi sebesar 90,70\%.

Pengujian Telegram Bot

Telegram bot merupakan hal yang penting dalam sistem, dimana akun pengguna akan disetting dan diprogram sehingga untuk dapat berinteraksi dengan NodeMCU dan berfungsi sebagai pengirim data. Proses pengiriman data dari sensor ke telegram bot menggunakan modul WiFi ESP8266 yang ada pada NodeMCU. Pada program NodeMCU ESP8266 di arduino IDE yang perlu dilakukan adalah setting jaringan internet yang akan digunakan terlebih dahulu yang meliputi setting ssid dan password. Pengujian mengirim data ini ditunjukan oleh gambar 3.

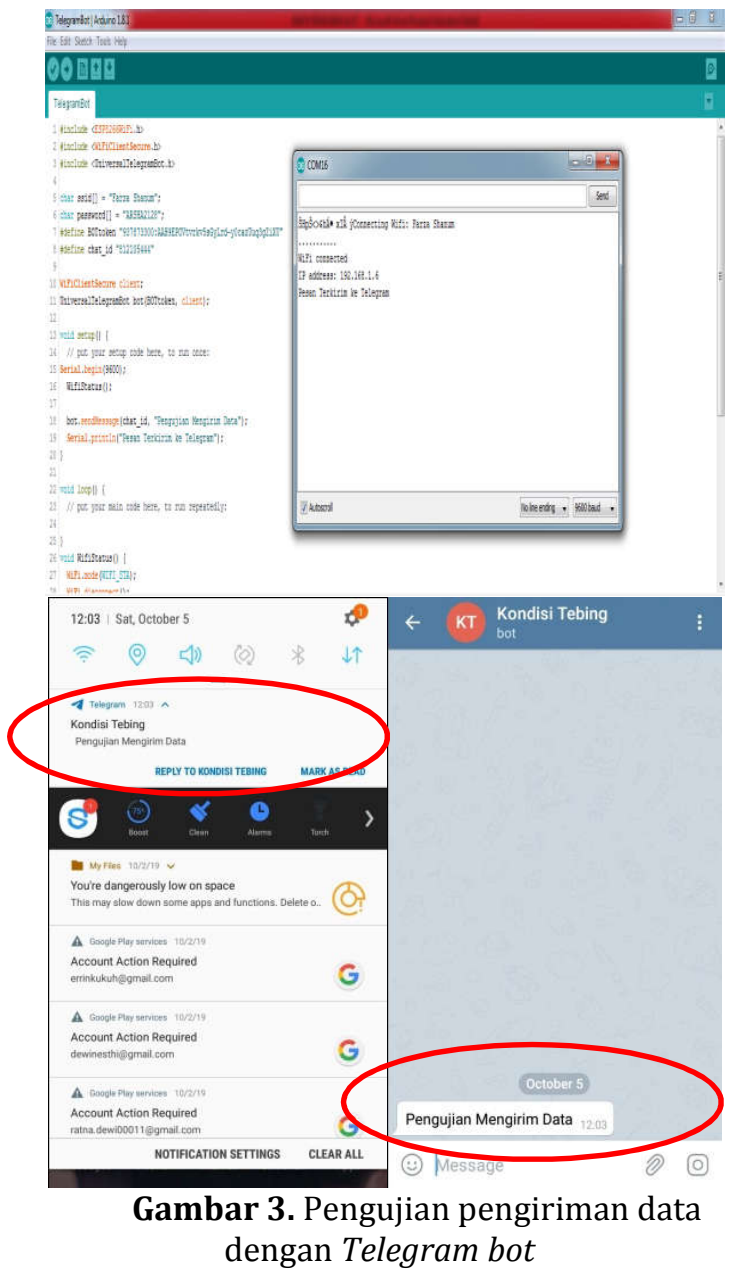

\section{Pengujian Seluruh Sistem}

Pengujian seluruh sistem dilakukan dengan mengetahui kemampuan aplikasi dan perangkat keras sehingga dapat memberi peringatan dini akan terjadinya bencana tanah longsor. Pengujian dilakukan dengan memperhatikan dua faktor utama penyebab tanah longsor yaitu kelembaban dan kemiringan tanah seperti diperlihatkan pada gambar 4. 


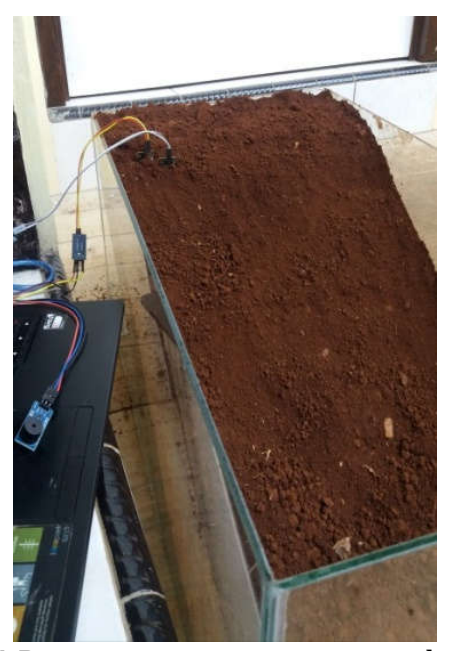

Gambar 4 Prototype pengujian sampel alat deteksi longsor

Tanah yang dipakai adalah lapisan tanah bagian atas yang secara alami sudah tercampur dengan lapisan lempung, hal ini diharapkan sesuai dengan kondisi lereng di Indonesia secara umum. Kemiringan tanah divariasi dengan 5 kategori sesuai dengan klasifikasi kemiringan lereng yang ditunjukkan pada tabel 3 (Anbalagan, 1992)

Tabel 3. Klasifikasi Kemiringan Lereng (Anbalagan, 1992).

\begin{tabular}{cc}
\hline Kemiringan Lereng & Keterangan \\
\hline$>45^{\circ}$ & Sangat Curam \\
$35^{\circ}-45^{\circ}$ & Curam \\
$25^{\circ}-35^{\circ}$ & Sedang \\
$16^{\circ}-25^{\circ}$ & Landai \\
$<15^{\circ}$ & Sangat Landai \\
\hline
\end{tabular}

Pengujian dilakukan dengan menempatkan sensor soil Soil Moisture FC-28 di beberapa titik. Untuk mendapatkan nilai kelembaban maka dialirkan air secara merata dari atas permukaan tanah seperti saat terjadinya hujan. Hasil yang didapat diperlihatkan pada tabel 4 , dimana semakin curam kemiringan lereng dan dengan kelembaban yang rendah sudah dapat meyebabkan terjadinya tanah longsor, begitu juga sebaliknya ketika kemiringan tanah tidak begitu curam akan memerlukan kelembaban tanah yang cukup besar untuk terjadinya tanah longsor. Sehinga pada pengujian ini terbukti bahwa tingkat kemiringan lerang dan kelembaban adalah berbanding terbalik

Tabel 4 Pengaruh kemiringan dan Kelembaban tanah pada tanah lonsor

\begin{tabular}{ccccc}
\hline \multicolumn{4}{c}{$\begin{array}{c}\text { Kemiringan } \\
\text { Nanah (o) }\end{array}$} & \multicolumn{3}{c}{$\begin{array}{c}\text { Kelembaban } \\
\text { Tanah (\%) }\end{array}$} \\
\cline { 3 - 5 } & $>45$ & $<15$ & $13-30$ & $>30$ \\
\hline 1. & $35-45$ & $<22$ & $22-45$ & $>45$ \\
2. & $25-35$ & $<27$ & $27-54$ & $>54$ \\
3. & $16-25$ & $<33$ & $33-67$ & $>67$ \\
4. & $<16$ & $<45$ & $45-90$ & $>90$ \\
5. & & & & \\
\hline
\end{tabular}

Pengujian sistem deteksi dini pada alat, memperlihatkan alat berfungsi dengan baik, dimana peringatan dini berhasil terkirim melalui pesan singkat pada aplikasi telegram messenger saat kondisi status siaga, sedangkan alarm akan berbunyi pada saat status bahaya sesuai dengan tabel 4 .

Alat ini akan sangat berguna bagi pemerintah dan masyarakat khususnya yang tinggal di daerah lereng pegunungan, dengan adanya tanda peringatan dini bencana tanah longsor diharapkan warga disekitar lokasi rawan bencana masih mempunyai waktu untuk menyelamatkan diri sehingga korban jiwa dapat diminimalkan.

\section{Kesimpulan}

Telah berhasil dibuat alat pendeteksi dini tanah longsor menggunakan NodeMCU berbasis melegram Messenger, dimana sistem mampu memberikan notifikasi yang ditampilkan pada telegram messenger berupa informasi nilai kelembaban tanah dalam persen (\%), kemiringan lereng serta keterangan kondisi statusnya (siaga atau bahaya) dengan peringatan tambahan berupa alarm berbunyi saat status bahaya terdeteksi. Akurasi nilai kelembaban tanah cukup akurat dengan nilai error sebesar 9,30\% dan persamaan linier $y=0.9929 x-2.5336$ dan nilai $\mathrm{R}^{2}=0.9965$ dan sistem mampu mengirimkan notifikasi dengan waktu kirim rata-rata 8,60 detik.

\section{DAFTAR PUSTAKA}

Anbalagan, R. 1992. Terrain evaluation and landslide hazard zonation for environmental regeneration and land use planning in mountainous terrain, International Landslide Symposium, hal. 861-868, Christchurch, New Zealand.

Fina, F. Nugraha, AL. dan Yuwono, BD. 2015. Pemetaan Risiko Bencana Tanah Longsor Kota Semarang. Jurnal Geodesi Undip Volume 4, Nomor 1 Tahun 2015. Universitas Diponegoro.

Gati, U. dan Caroline, J. 2018. Analisis Pengaruh Perubahan Kadar Air Terhadap Parameter Kuat Geser Tanah. Seminar Nasional Sains dan Teknologi Terapan VI. Surabaya: Institut Teknologi Adhi Tama Surabaya.

Hary, HC. 2006. Penanganan Tanah Longsor dan Erosi, Gajah Mada University Press. Yogyakarta

Karnawati, D. 2001. Sistem Peringatan Dini Tanah Longsor dengan Pemberdayaan Masyarakat, Lokakarya Nasional : Pengembangan Sistem Peringatan Dini, PSBA UGM - PMI Pusat, Yogyakarta.

Lutfiyana, Hudallah, N. dan Suryanto, A. 2017. Rancang Bangun Alat Suhu Tanah, Kelmebaban Tanah, dan Resistansi. Jurnal Teknik Elektro Vol. 9 No. 2. Universitas Negeri Semarang.

Mardhatillah, E dan Wildian. 2017. Rancang bangun sistem peringatan dini tanah longsor berbasis mikrokontroler atmega328 menggunakan metode penginderaan berat, Jurnal Fisika Unand Vol. 6, No. 2, April 2017, ISSN 2302-8491

Mudhrikah A. 2015. Estimasi kerawanan tanah longsor dengan mengguankan metode scoring studi kasus: sub dan keduang. Skripsi S1 Teknik Pertanian, Universitas Gadjah Mada 
Nandi. 2007, Longsor, Jurusan Pendidikan Geografi, Bandung, FPIPS-UPI.

Paimin, Sukresno dan Irfan Budi P. 2009. Teknik Mitigasi Banjir dan Tanah Longsor. Bogor: Tropenbos International Indonesia Programme.

Ridho'i, A., Priyawan S. dan Sutriono B. 2015. Perancangan deteksi longsor di bukit watu buceng dusun ketos desa wonodadi kulonsari, Jurnal Pengabdian LPPM Untag Surabaya Nopember 2015, Vol. 01, No. 02, hal 111 118

Silvianingsih, Liliawarti, dan Satwarnirat. 2015. Pengaruh Kadar Air Terhadap Kestabilan Lereng (Kampus Politeknik Negeri Padang). Rekayasa Sipil Volume XII Nomor 2. Politeknik Negeri Padang.
Tejo, R.K, Baskoro, D.P.T, dan Barus, B. 2016. Regresi logistik biner dan rasional untuk analisis bahaya tanah longsor di kabupaten cianjur. Jurnal Ilmu Tanah dan Lingkungan IPB, Vol 18 No.1, hal: 35-41

Widhiantoro, D. 2016. Purwarupa Sistem Pendeteksi Tanah Longsor Menggunakan Ultrasonik Dan Infrared Dengan Notifikasi Sms, Jurnal Kajian Teknik Elektro (JKTE), Vol.1 No.2, hal 132-137

Yahwe, CP., Isnawaty, dan Aksara, F. 2016. Rancang Bangun Prototype System Monitoring Kelembaban Tanah Melalui SMS Berdasarkan hasil penyiraman Tanaman "Studi Kasus Tanaman Cabai dan Tomat". Jurnal semantik Vol.2, No.1, ham. 97-110 